\title{
A Critical Mathematics Education for Climate Change
}

A Post-Normal Approach

\author{
Richard Barwell and Kjellrun Hiis Hauge
}

\begin{abstract}
Climate change is an urgent global challenge. Responding to climate change requires significant critical mathematical understanding on the part of all citizens. In this chapter, we consider what a critical mathematics education for climate change might look like. We draw on ideas from Skovsmose's work, including the notion of formatting, as well as the body of work known as post-normal science. As a starting point for pedagogical reflection, we propose twelve principles, operating within landscapes of investigation, and organised into three groups relating to: forms of authenticity; forms of participation; and reflection on and with mathematics. We illustrate these ideas with an example of a possible landscape of investigation relating to historical temperature change.
\end{abstract}

\section{Keywords}

critical mathematics education - post-normal science - climate change - formatting landscape of investigation

In January 2019, Greta Thunberg, then a 16-year-old school student from Sweden, addressed the World Economic Forum in Davos, Switzerland. She told the assembled leaders of industry, nations, and billionaires, "I want you to panic." Her speech ${ }^{1}$ made headlines around the world. She was speaking about climate change:

Either we prevent $1.5^{\circ} \mathrm{C}$ of warming or we don't. Either we avoid setting off that irreversible chain reaction beyond human control or we don't. Either we choose to go on as a civilisation or we don't. That is as black or white as it gets. There are no grey areas when it comes to survival.

(C) RICHARD BARWELL AND KJELLRUN HIIS HAUGE, 2021 DOI: 10.1163/9789004465800_008 
The moral force of her speech was one of the reasons it went round the world. She challenged powerful people for thinking too much about money and growth, and not enough about survival. She challenged them to act. Her speech and the crisis that prompted it raise many questions. What should we, as mathematics educators, be doing about this crisis? How can we prepare today's young people to act? How can we ensure that citizens understand supposedly simple ideas like " $1.5^{\circ} \mathrm{C}$ of warming" or a carbon budget?

Critical mathematics education research has mostly focused on questions of social justice, with little attention to questions of environmental sustainability, such as the threat of climate change. ${ }^{2}$ Our planet faces an array of complex, challenging environmental problems, including mass extinctions, pollution, habitat loss, and climate change. Moreover, mathematics plays a key role, both in understanding such problems and in making possible the technologies that contribute to them (Barwell, 2018). Critical mathematics education, in combination with a perspective on complex environmental problems called postnormal science (see below), offers a valuable framework with which to think about the role of mathematics and of mathematics education in response to these problems (Hauge \& Barwell, 2017). In particular, we have worked on the question of how mathematics educators can prepare teachers to educate future citizens to participate in the democratic debates these problems will engender. In this chapter, we focus on the specific issue of climate change. Our purpose is to explore what this theoretical work might mean for mathematics classroom practice. To do so, we first review some of the relevant context in relation to climate change and, in the next section, summarise some key theoretical ideas. We then propose a set of principles derived from our theoretical position and designed to inform classroom practice. Our aim is to prompt more thinking on what a mathematics pedagogy for the climate might look like. The principles we propose are therefore offered as a starting point, which we illustrate with an example of a possible activity.

\section{$1 \quad$ Our Changing Climate}

Climate change is undoubtedly one of the most serious problems faced by humans, since it is likely to radically modify our planetary weather systems and ecosystem in possibly dangerous ways. There is strong evidence that the emission of greenhouse gases like carbon dioxide and methane, largely as a result of human activity, is affecting the equilibrium of the climate system (Intergovernmental Panel on Climate Change [IPCC], 2018). Hence, the atmosphere, the oceans, and the cryosphere (glaciers and polar ice caps) are becoming 
warmer. This warming affects weather patterns in unpredictable ways, with consequential impacts on a wide range of ecosystems, as well as on humans. Documented effects include changes in the spread of insect-borne diseases, increased drought or flooding, increased intensity of hurricanes, increases in damage caused by forest fires, reduced polar ice cover, migration of species towards the poles, coral bleaching, to name just a few (IPCC, 2018). In 1980, the United Nations created the Intergovernmental Panel on Climate Change (IPCC) to review the known science on this topic and produce regular reports. The most recent report concluded:

Human activities are estimated to have caused approximately $1.0^{\circ} \mathrm{C}$ of global warming above pre-industrial levels, with a likely range of $0.8^{\circ} \mathrm{C}$ to $1.2^{\circ} \mathrm{C}$. Global warming is likely to reach $1.5^{\circ} \mathrm{C}$ between 2030 and 2052 if it continues to increase at the current rate. (IPCC, 2018, p. 6)

The reference to $1.5^{\circ} \mathrm{C}$ is significant: in December 2015, governments from around the world signed the Paris Agreement, committing themselves to take steps to limit warming to this amount. ${ }^{3}$

Climate change is a complex scientific problem, but addressing climate change also leads to many social and political tensions. For example, the most straightforward measure to minimise climate change would be to immediately halt the extraction of fossil fuels, as well as their consumption in transportation, power generation, and other large-scale processes. Unfortunately, of course, such a measure would drastically affect the way of life of most people on the planet. As Greta Thunberg pointed out, there are many reasons relating to money and growth why such measures are difficult to put in place. Deciding what to do about climate change has therefore become a highly politicised issue, involving multiple lobbying groups, some overt, others covert, all attempting to influence national and international policies. Climate change is increasingly an issue in elections, and its impacts can destabilise societies (e.g., through drought or crop failures) around the world. Tackling climate change has therefore become a space of fierce debate, where sceptical voices have a presence out of proportion with their number. Media outlets give space to sceptics, often in an effort to be "fair and balanced," despite overwhelming scientific consensus on the nature and causes of climate change, and the increasing acceptance of the population at large in many countries. In an era of fake news, however, it can sometimes be difficult to know whom to believe.

The role of mathematics in all of this is substantial. Mathematics is involved in describing, predicting, and communicating climate change (Barwell, 2013). It is used as a tool to describe and understand the changes that are happening, 
as well as the nature of the climate system. Mathematics is used to develop powerful models to make predictions about the future evolution of the climate globally, regionally, and increasingly, locally. Mathematics is also used to communicate the nature and impacts of climate change among scientists, as well as for policymakers, politicians, the media, and the general public. Mathematics, then, is important for the scientists researching climate change, but it is also important for the people developing plans to reduce the severity of future climate change and to mitigate its effects. Mathematics is also important for citizens engaging with the debates about climate change. The claims of many climate sceptics, for example, draw on mathematical arguments. Citizens need a critical awareness of how mathematics is used in arguments in order to develop an informed understanding of the issues, make reasoned decisions, and participate in democratic debate. They also need an informed understanding of how mathematics cannot provide precise assessments or solutions because of uncertainty inherent in such complex situations. Finally, citizens need an awareness of the (often overlooked) role of values in relation to the mathematics and science of climate change. In the next section, we develop these points, drawing on ideas from critical mathematics education and postnormal science.

\section{Critical Mathematics Education and Post-Normal Science}

In our previous work, we have developed the position that for mathematics education to adequately address issues like climate change, ideas from critical mathematics education need to be supplemented with a theorisation of the nature of science and its role in society in the context of complex environmental problems (see Barwell, 2013; Hauge \& Barwell, 2017). For this latter theorisation, we draw on the philosophy of post-normal science (Funtowicz \& Ravetz, 1993), which specifically conceptualises the nature of problems like climate change. It characterises such problems needing post-normal science in the search for solutions. This term indicates that such problems cannot be solved through "normal" science (in the sense of Thomas Kuhn) in which scientists choose a scientific problem that is solvable in accordance with peerreviewed theories and methodologies. Normal science problems are usually clearly defined within closed systems, often with a high level of predictability. Post-normal situations, in contrast, have three important features: a high level of conflict, a high level of uncertainty, and a high level of urgent risks. These features are apparent in the case of climate change. The associated stakes are conflicting so that decisions on how to respond to climate change, 
or indecision, affect people around the world differently. The climate system and the evolution of climate change over time are complex, involving interactions throughout the planetary ecosystem. The effects of greenhouse gas emissions, for example, are not restricted to the location of the emissions: they can contribute to changes in oceans, polar ice caps, or rainfall many thousands of miles from their source. This means there is also a high degree of uncertainty: a perfect description of the climate system is impossible, there are many factors that science does not include, and the multiple interactions of the system mean that future states cannot be predicted with certainty. The IPCC reports (e.g., 2018, p. 8), for example, present a range of scenarios with associated probabilities, rather than a specific prediction for future climate change. Finally, climate change involves a high degree of risk if no action is taken or whatever course of action is taken. Business as usual is expected to lead to catastrophic climate change impacts, but the proposed interventions may also have unforeseen consequences on the ecosystem or on human society or both.

A central feature of post-normal situations is the importance of values. Deciding which measures to take in the light of climate change is not simply a question of (normal) science. Climate change is too closely interwoven with human society and its collective and individual choices. To give one example, climate change is reducing the summer extent of arctic sea ice, meaning that commercial shipping and oil exploration are becoming possible in the arctic ocean (IPCC, 2018). Whether to exploit these opportunities is not really a scientific question: such decisions depend on values, such as the relative importance we ascribe to protecting the arctic wilderness versus exploiting new economic opportunities. There is no purely scientific way to make this choice.

From the perspective of post-normal science, these features of post-normal situations mean that citizens need to be more involved in the scientific process. If the problem is completely interwoven with human society, then the weighing of evidence and the development of responses must involve members of society beyond the scientific community. Funtowicz and Ravetz (1993) refer to this idea as an "extended peer community," to allow for the values dimension of problems like climate change to be debated and discussed, in the light of values, complexity, uncertainty, and risk. More broadly, citizens need to be involved in the political debates around proposed measures, many of which will have a direct impact (not always negative) on their lives.

Given the strong mathematical component in climate science and all of the associated debates, if citizens are to participate in the extended peer community, we must ask what kind of preparation they need (Hauge \& Barwell, 2017). In particular, what kind of mathematics education could prepare them to contribute to democratic processes around climate change? To respond to 
this question, we draw on critical mathematics education and, specifically, on Skovsmose's concepts of formatting and realised abstraction. Formatting refers to the embedded role of mathematics in contemporary technologically mediated society. While mathematics is ubiquitous, particularly through the use of models and algorithms, its role is often invisible. The idea of formatting is that this human-designed mathematics has real social effects: our lives are organised by mathematics. This mathematics makes possible activities that risk exacerbating climate change. For example, consumer society is organised by mathematical systems that make possible a highly internationalised process of production and delivery, which results in cheaper mass-produced products, but with high levels of production-related and transport-related emissions.

Skovsmose refers to the way in which mathematics becomes part of social reality as realised abstraction. Mathematics, particularly in the process of modelling, is used to describe different aspects of reality. These descriptions, however, can become prescriptions, dictating how people should behave. Systems of taxation, for example, are based on economic models that describe flows of income and revenue within the economy and project government revenues according to whatever general principles a government considers as fair and wishes to implement. These mathematical models are realised abstractions: they have real effects in the lives of people. Climate change can also be thought of as a realised abstraction (Barwell, 2013). Our understanding of climate change is largely based on mathematical models, whether to provide broad descriptions of the changing climate or develop predictions of future changes. These models form the basis of government policy, commercial choices, and individual decisions. Climate models thus become part of social reality. Students, as future citizens, therefore need opportunities to develop a "reflective" knowing (Skovsmose, 1994) of the mathematics of climate change that includes awareness of the role of mathematics in causing climate change and in understanding climate change (Barwell, 2013).

In this section, we have summarised some key ideas with which we can think about mathematics education and climate change. Mathematics is a central part of climate science, and the debates about how to respond to climate change. As a post-normal situation, these debates need the wide involvement of citizens in various forms of democratic processes, including as contributors to an extended peer community connected with the sciencepolicy process. These debates involve a range of values, and must address the complexity, uncertainty, and risks associated with climate change. Science alone cannot determine how to respond. For citizens to participate in these debates, they need to be able to engage at some level with the mathematics of climate science and they also need an understanding of the formatting role of 
mathematics in a technological society. The question now arises of what mathematics teaching for climate change (or for any post-normal situation) might look like. In the next section, we propose some principles to guide mathematics teaching in the context of climate change.

\section{Mathematics Teaching and Climate Change}

The following principles are derived from the theoretical ideas in the previous section and are informed by our earlier work developing mathematics classroom tasks (Coles et al., 2013; Hauge, 2016a; Hauge et al., 2015), classroom observations, and a survey of teachers in Norway and Canada (Abtahi et al., 2017). Our principles are organised into three groups: forms of authenticity, forms of participation, and reflecting on and with mathematics. We see these principles as a starting point for thinking about mathematics teaching in relation to climate change, rather than as a definitive set of empirically validated standards. How they are interpreted, applied, or modified will vary greatly from place to place and from one classroom to another. The principles are summarised in Table 8.1. For clarity, we present them as normative principles, setting out how, for us, based on our previous work, mathematics education for climate change could look. As such, we assume that they will be challenged and contested. Ultimately, our goal is to prompt the reader to consider what principles they would propose or adopt. Our principles are illustrated in the final section by an extended example.

\subsection{Forms of Authenticity}

We propose four principles relating to forms of authenticity. Post-normal situations such as climate change affect all our lives, but they can seem rather abstract or dispersed: as a realised abstraction, it is difficult for individuals to "see" climate change (which is one reason why mathematics is an important tool in understanding it). It is therefore important for students to engage with climate change authentically, so that they understand its concrete impact in their own current or future lives. Moreover, the development of reflective knowing in relation to climate change is likely to be more effective if students have a direct, authentic connection with the tasks and activities they encounter in the mathematics classroom.

The first principle relating to authenticity is to use problems about climate change that students find relevant in their lives. In many cases, relevant problems may be based on local climate concerns and issues, focusing on, for example, exploring changes in local climate, local greenhouse gas emissions, or local 
climate change impacts, such as on flooding, local biodiversity, or commercial interests. In other cases, however, students may identify problems arising from their own interests and engagement with related topics such as international development, human rights, business, or politics. An interest in animal welfare, for example, might lead to a focus on arctic ice cover in relation to projected extinction of polar bear populations. By working on relevant problems, students are more likely to perceive and consider the complexity of these problems (Appelbaum, 2009; English \& Gainsburg, 2015; Kaiser \& Schwarz, 2010).

Second, students should work with real data as much as possible. Real data, as opposed to made-up data, can be collected or generated by students through observation or surveys, or can be obtained from publicly available datasets. In many countries, for example, climate data is available online, and much other data can be located on greenhouse gas emissions and many other topics. One role of teachers, in relation to the use of real data, is to support students to access and filter the data: large online datasets may be unwieldy and teachers may need to make some initial selections or help students to make such selections. The use of real data can allow students to appreciate the often-messy nature of climate data or emissions data and discuss aspects of uncertainty, such as how to deal with missing data, changes in measurement protocols, or unmeasurable phenomena (e.g., English \& Watson, 2018).

Third, students' own ideas and values should have a central role. Mathematics is a human activity, and investigating topics like climate change should enable students to understand the nature and effect of human mathematising. Students could, for example, discuss what data to collect or which variables to include in a model. They could also consider what important aspects of their problem are difficult to mathematise, such as psychological or aesthetic impacts. This kind of approach can provide some insight into the role of values in climate science and can lead to some awareness of how values shape the choices of others, such as politicians or scientists.

Fourth, students should have the opportunity to engage in meaningful debate relating to climate change, based on their mathematical investigations. We do not propose that teachers should impose a particular agenda about climate change, other than that it is a pressing global problem. Through thoughtful use of mathematics, students can develop a deeper, critical understanding of the issues and more clearly thought-out responses (Appelbaum, 20o9; Hauge \& Barwell, 2017).

An example of an activity that displays authenticity can be found in Coles et al. (2013). The activity, which is from the U.K. context, involves collecting publicly available data about flood risk and intersecting it with data about property values for the area in which students live. The activity involves important 
mathematics, notably about probability, the formal calculation of risk, as well as data handling. By focusing on the local contexts, questions and discussion are likely to be meaningful for students. The activity leads to questions about where to invest resources to mitigate climate change in relation to property values.

\subsection{Forms of Participation}

The second group of principles relates to forms of participation. These principles arise, in part, from the need to prepare students to contribute to extended peer communities. They therefore need to be exposed to the communication of mathematical ideas and the use of mathematics in debate and deliberation. These principles also relate to aspects of critical mathematics education that emphasise the importance of dialogue in the development of critical awareness.

The first principle is simply that students should participate in mathemat$i c s$. We mean here that the role of students should be an active one, in which they do much more than solve problems provided by the teacher. Rather, they should be participants in the selection of problems, the mathematising of problems, the selection of data, the selection of mathematical tools, the construction of models, among other things. This principle is not, of course, specific to climate change, but is widely proposed in different forms in relation to a problem-solving approach to mathematics teaching (see, for example, Barbosa, 2007). Active participation in mathematics is a key principle that permits students to reflect on mathematics, as discussed in the final set of principles.

Second, students should actively participate in their classrooms. Participation in mathematics could be an individual activity, but we wish to emphasise the collective nature of classroom participation. Students may work together in small groups, share their work with classmates, discuss and critique each other's work, and reflect on each other's findings. If students are not familiar with this kind of group working, teachers may need to structure their participation in order to cultivate productive collaboration.

Third, students should actively participate in their communities. These communities could include their school, the communities in which they live, or mathematical communities. Investigating climate change is not simply an interesting context for learning mathematics: the results of students' work can inform many aspects of school life and that of the surrounding community, such as in relation to energy consumption, traffic patterns, or local political action. Students could collect data from community members, such as asking local elders about their experience of climate changes, or conducting a survey 
about recycling. The results of students' investigations could lead to presentations to local politicians or municipal representatives, letters to local newspapers or proposals to school leaders (for examples of community participation in mathematics teaching, see Appelbaum, 2009).

Fourth, students should actively engage with and participate in public debate. Public media, for example, can provide many starting points for mathematical activities, including television or newspaper reports, opinion pieces, blogs, and government statements and policies. Students can also present their findings as responses to positions noted in public debate, supporting, refuting, or critiquing different opinions. Again, this work could lead to communication with local or national politicians or newspapers.

The following example illustrates some of these forms of participation (although it does not directly concern climate change). The project concerned traffic safety and was conducted by a class of high school students in Norway (Hauge, 2016b; Hauge \& Barwell, 2017). Close to the students' school, there was a stretch of road which the school bus passed every day, and where cars had driven off the road and into the sea. A person had died the year before the project. The road barriers had been too low to prevent these accidents. With protection from the police, the students measured traffic and the heights of the barriers. The local newspaper covered the story. The teacher's aim was to use statistical concepts found in the curriculum, and to show how mathematics can make a difference as a useful tool in argumentation. She developed and discussed the project together with her students. Through this project, the students participated to make sense of data, information, and arguments. They participated in discussion and debate within their student body, as members of the community, and they considered possible responses and contributions to a public debate. Two months after the data collection, the measured barriers had been replaced by new and taller ones.

In another project more closely connected to climate change, high school students were invited to discuss and debate the possibility of opening up the offshore area near their town to oil exploitation (Hauge \& Barwell, 2017). The students were asked to provide argumentation based on their own opinions. After a session with related group tasks, they discussed oil exploitation in a plenary session. The debate reflected the complexity of the issue at hand and included consideration of economic opportunities, the development of their home town, and possible impacts on fish stocks, fisheries and tourism. Although the students disagreed on the matter, they explored each other's arguments with respect. This is an example that shows that controversial issues in classrooms can be fruitful as they may be engaging for students. 


\subsection{Reflecting on and with Mathematics}

Our final set of four principles concerns reflecting on and with mathematics. These principles are particularly derived from the critical mathematics education idea that students need to understand the role of mathematics in shaping their society and their lives, as well as the role of mathematics in understanding problems like climate change. These principles also tackle the potential role of students in all forms of participation, and particularly in public debate, promoting the development of a critical awareness of how mathematics is used (or misused) to communicate information, advance positions, serve interests, and undermine opponents.

The first reflection principle is that students should have opportunities to reflect on how mathematics is useful. By working on authentic tasks and engaging in various forms of participation, students should develop some valuable sense of what mathematics can make possible. For example, mathematics can clarify an underlying warming trend in messy temperature data that would otherwise be difficult to observe, and certainly difficult to physically experience in many places. This principle is coupled with the second: that students should have opportunities to reflect on the limits of mathematics. Again, having worked on authentic tasks, students should have a sense of what mathematics cannot do. Mathematics cannot calculate what level of emissions is acceptable, since "acceptable" is a value-laden term. Mathematics cannot easily model emotions such as what it feels like when your house is flooded. Mathematics cannot easily model the significance of disappearance, such as the extinction of species of fish or insects that result from warming oceans or changes in seasons. Mathematics can, to some extent, model fish or insect populations, but it cannot capture the tragedy of extinction: the loss of a creature, of its place in an ecosystem, of its missing beauty (Barbosa, 2007; Barwell, 2018; Hauge \& Barwell, 2017).

The third reflection principle is that students should consider the role of values in mathematics. In particular, students should think about how values shape their choice of project, their choice of data, and their interpretation of their findings. For example, in a project on climate impacts on local farms, some students might be motivated by economic considerations, such as loss of income for farmers, while others might be motivated by a concern for biodiversity. Their choice of which data to collect could be influenced by these motivations. The interpretations of their findings would emphasise their preferred interests and downplay other considerations. By engaging in participation in the classroom, and in the community, students would have the opportunity to reflect on how their mathematical activity is shaped by values relevant to the situation (see Pratt et al., 2011). 
The final reflection principle is that students should have opportunities to reflect on uncertainty and consider different ways to deal with it. Through their authentic activities, students are likely to encounter various kinds of uncertainty, including an inherent level of imprecision in their data, the absence of some kinds of data, and the possibility of unrecognised factors influencing a situation. For some students, such discussions could be an opportunity to explore statistical techniques for managing imperfect data or evaluating different sorts of uncertainties (see Hauge \& Barwell, 2017). For others, the discussion is a chance to understand the role of uncertainty in shaping thinking about climate change and the decisions that are made as a result of mathematical analyses.

TABLE 8.1 Principles for teaching mathematics in the context of climate change

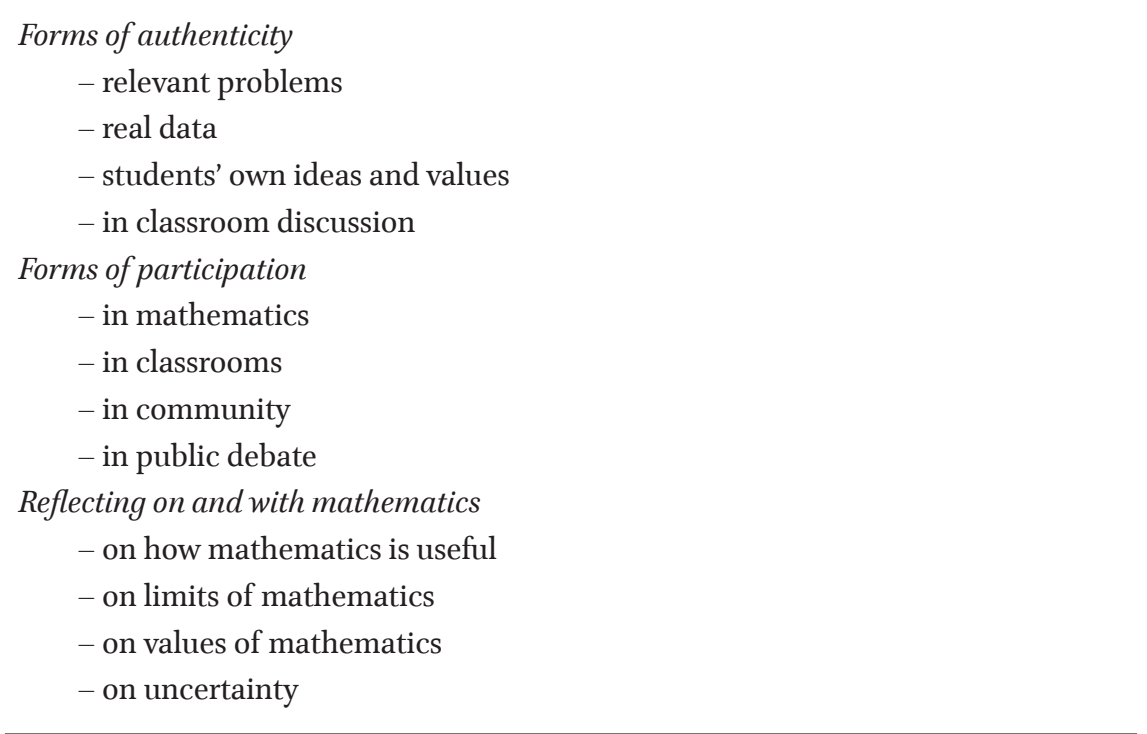

In the rest of this chapter, we exemplify the principles we have proposed through an example of a possible mathematics classroom project. We see the project as offering a "landscape of investigation" (Skovsmose, 2011) in which students can explore climate-related topics and related mathematics. Skovsmose (2011) defines a landscape of investigation as an activity where students explore mathematical characteristics through asking questions such as "What if ...?" The teacher invites the students into the landscape, but in order to call it a landscape of investigation, the invitation must be accepted. This means that the task is open in the sense that exploring can take students in different directions, where there might be no correct or wrong answers, and where the 
landscape is appealing to the students so that they wish to explore it through posing their own "what if" questions. Some aspects of our approach are also similar to Appelbaum's (2009) notion of "taking action," in which explorations akin to a landscape of exploration extend into engagement with real-world, community-based problems. The traffic survey is a good example of taking action. The project involved a degree of student direction and their work was taken up in their community.

In adopting this kind of approach, it is clear that we have made some assumptions about the role of learners and teachers in this process. We assume, for example, that at some level, students are concerned about environmental sustainability. While we know many students have these concerns, we realise not all students will see the relevance. Indeed, we do not wish to impose a particular environmental ideology on students through mathematics teaching. We see the idea of a landscape of investigation as helpful in addressing this implicit tension. The metaphor of exploring a landscape suggests that teaching should follow students' interests, rather than dictating the direction of the work. This position in turn assumes particular demands on the teacher: to be open to students' interests and willing to follow and support them. In the example about oil exploration, for instance, students' level of participation varied, with some more actively engaged than others. Not all students were motivated by environmental considerations; some were more concerned about the jobs and economic development that they assumed oil extraction would bring. The point is, the exploration of a particular landscape allowed for an exploration of different ideas and perspectives. In the following, we sketch a task that may develop into a landscape of investigation.

Investigation: What Was the Temperature on Your Birthday?

In many countries, extensive historical weather data is available online. In Norway, for example, the Norwegian Broadcasting Corporation together with the Norwegian Meteorological Institute keeps track of weather data, which is accessible online for anyone. ${ }^{4}$ In one online service, you can choose a certain date in a certain year and check what the weather was at a chosen place in Norway. For a few cities, the measurements go back to 1902, but there are still data for the weather further back in time. The data provided, depending on how far back in time it goes, consist of temperature, wind strength, and a symbol showing whether it was a rainy or sunny day. Similar datasets are available in the other countries, including the United Kingdom, Canada, the United States, and Australia. In some cases, schools might even have their own datasets. 
The premise of this investigation is that students look up temperature data (or other weather data) on the date of their birth, and in the location of their birth (or their current place of residence), for each year of their life, and going back in time. Depending on the age of the students, support may be needed to access and extract the relevant data. A balance needs to be struck between providing a "clean" dataset and struggling with complex, messy databases. In many cases, extracted data may contain gaps or corrections, such as when, for example, measuring equipment is upgraded. It is important for students to consider how to deal with such situations.

Having extracted the data, students should consider how to explore it. Calculating averages and making a graph of temperatures over time are obvious possibilities. These are tasks in which students can work with real data, and with individual time series, including all their flaws. Students can discuss what temperature data to include in a graph: the mean temperature, the temperature at a certain time of the day, or other. Similarly, students can consider and discuss whether to work with averages such as mean daily temperature, mean decadal temperature, or mean temperature anomalies. The aim of such activities is to discuss global warming and consider whether there is a trend towards warmer temperatures. The students' graphs will not all be the same, and each graph is likely to show significant variation. With young students, it may be sufficient to draw on their experiences to discuss variation in weather, what influences the weather, what a trend is, and the difference between weather and climate. Older students can develop moving averages, where they can explore what happens when they exchange data points with averages of three, four, or more data points, to see what it reveals with respect to possible trends. In addition, students can use software to produce linear regressions. Students can also explore questions about how the temperature on their birthday may evolve in future years.

Will students' data and analyses demonstrate the occurrence of global warming? This question can initiate a discussion that covers all four elements of reflecting on and with mathematics. Students can reflect on the usefulness of the data and the ways that mathematics was applied to show various pictures of how the temperature has changed over time. At the same time, students can reflect on the ways in which mathematics does not provide clear answers. Uncertainty is apparent, both in the form of natural variation and lack of knowledge, which may involve indeterminate aspects in the data or in mathematics. How to deal with such uncertainties is a key question in policymaking. Students could go on to explore the $1.5^{\circ} \mathrm{C}$ target set out in the Paris Agreement by searching for information online. In light of their investigations into the temperatures on their birthdays (see Figures 8.1 and 8.2), students 
The weather 31st of August

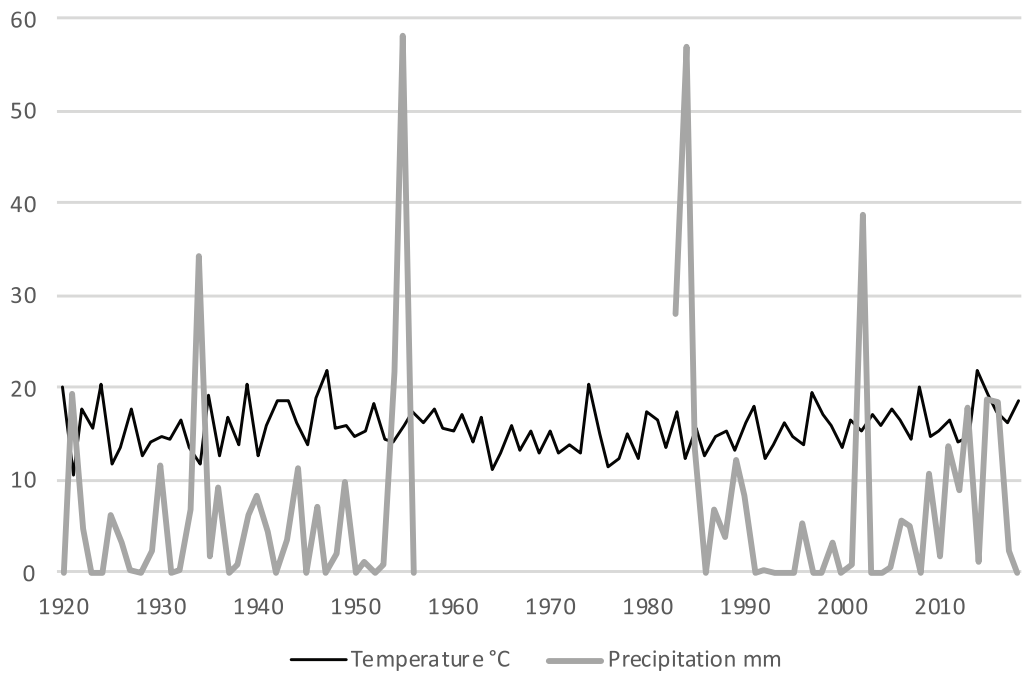

FIGURE 8.1 Temperature and rain in Bergen, Norway, August 31st since 1920 (www.yr.no). Relevant topics to explore include: Describe the weather illustrated in the graph. The temperature is taken at alternately 1 and 2 a.m. Do you think this matters? What do you think the graph looks like in the years where rain was not measured? What is the difference between climate and weather? Does the graph show that the climate has changed over time? What other data could give better information on climate change?

\section{Temperature 31st of August}

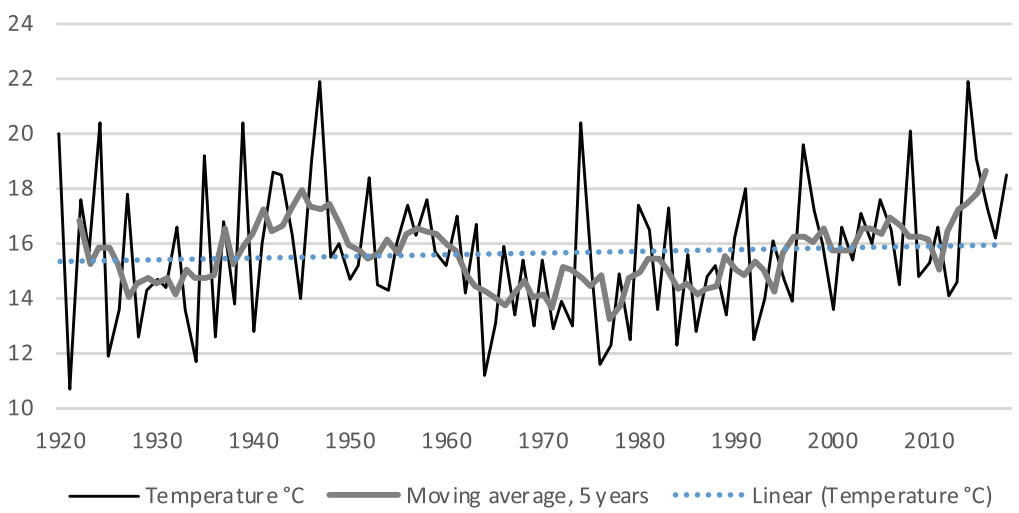

FIGURE 8.2 Temperature in Bergen, Norway, August 31st since 1920 (www.yr.no) together with moving average of 5 years and a linear regression. Relevant topics to explore include: Describe the trends in temperature over the years. How do you perceive this presentation compared to Figure 8.1? Does the graph show that the climate has changed over time? What other data could give better information on climate change? 
could discuss how one might know whether the target is reached. Indeed, students can reflect on what it means to reach this threshold - does it refer to temperature on one day, in one year, or in one decade? This issue is also an opportunity to discuss whether mathematics is an objective enterprise or whether values can be hidden in mathematics or promoted through mathematics.

Our proposed investigation is a potential starting point for a more developed landscape of investigation. Having completed the initial opening tasks we have suggested, students can be prompted to generate questions for further investigation individually or in groups. For example, students might: compare temperature trends on the birthdays of two or more students; investigate how temperatures have changed or not further back in time; discuss the quality of older data; explore other data, such as for wind, precipitation, snow cover, frost, and so on; explore data for other locations, regions, or the globe; examine web sites to see how mathematics is used in argumentation; and discuss possible values hidden in the mathematics.

The landscape of investigation we have outlined illustrates the principles for a mathematics education of climate change that we have proposed in this chapter. The activity involves four forms of authenticity. Students are invited to examine weather data for their own community, for which the impacts of climate change are likely to be very relevant. It involves working with real data. It allows students to introduce their own ideas and values, such as through selecting data, making decisions about data gaps and errors, and choosing how to interrogate the data and report their work. In addition, the activity assumes that students will engage in meaningful discussion of their work: that is, they are not expected simply to find the answer to a standard question; rather, they are expected to think authentically with mathematics as it relates to their community and their lives.

The investigation also involves four forms of participation. Students are participating in mathematics by making decisions about the questions, choice of data, treatment of data, analysis, and presentation of their work. Students are not simply asked to apply a pre-prepared process or algorithm. Students are participating in their classroom, through discussing their work with peers, with their teachers, and in whole class discussion. These discussions should encourage critique of each other's ideas, as a way to explore the limits and values embedded in the mathematical processes. The investigation prompts participation in students' communities outside of school. Students should consider what their findings mean for their community and the surrounding ecosystem, and they can be encouraged to explore these findings with community representatives, such as parents, school administrators, local counsellors, 
and others. Finally, the investigation prompts participation in public debate, through, for example, participation in public discussions in school, in the media, in the town hall, or at their parliament.

Finally, the investigation creates possibilities for reflection. Students may reflect on the mathematical methods and concepts they use. For example, they can, depending on their age, develop deeper understanding of concepts of mean, moving average, modelling, and linear regression. Further, however, the investigation is an opportunity to reflect on how these concepts and techniques are useful in understanding climate change, as well as the limits of these concepts and techniques. For example, techniques like moving averages are useful in discerning underlying trends, but are limited in focusing on a narrow measure of climate. Students can also reflect on the role of values by thinking about, for example, how information and data is selected for their investigation, in relation to what mathematical techniques can include. Finally, students have opportunities to think about different forms of uncertainty, such as in the treatment of missing data, the treatment of variation, and the limitations of different sources of data. In considering possible future trends, students encounter even more starkly the uncertainty inherent in projecting future climate.

\section{$5 \quad$ Concluding Remarks}

Climate change is a global problem that is becoming increasingly urgent. As mathematics educators, we are concerned that this situation is not being sufficiently addressed in mathematics classes, mathematics curriculum, and mathematics education research. In this chapter, we have reviewed the recent synthesis of ideas of critical mathematics education and post-normal science and have used these ideas to propose a set of pedagogical principles for the development and organisation of mathematics classroom activities related to climate change. By proposing activities that involve students in different forms of authenticity, different forms of participation, and in different reflections on and with mathematics, we believe that students will develop a critical understanding of the nature of climate change as well as of the role of mathematics in relation to climate change. This role includes the use of mathematics to study climate change, but also the role of mathematics in the organisation of the consumer society that is driving climate change. Students may also appreciate the role of mathematics in critiquing this society. As mathematics educators, we contribute to treating students as citizens in the present and in their preparation to be the citizens of tomorrow; the citizens who will be called on 
to deal with the unsolved problem of climate change and its consequences. We believe that we must prepare these future citizens to have a critical understanding of the role of mathematics and its limitations in relation to the difficult decisions they will need to take.

\section{Notes}

1 https://www.theguardian.com/environment/2019/jan/25/our-house-is-on-fire-gretathunberg16-urges-leaders-to-act-on-climate

2 Of course, environmental sustainability is intimately related to issues of social justice, as reflected in the current UN sustainable development goals. It is therefore surprising to us that there has not been more critical mathematics education work on environmental issues.

3 https://unfccc.int/process-and-meetings/the-paris-agreement/what-is-the-paris-agreement

4 https://www.yr.no/klima/

\section{References}

Abtahi, Y., Gøtze, P., Steffensen, L., Hauge, K. H., \& Barwell, R. (2017). Teaching climate change in mathematics classrooms: An ethical responsibility. Philosophy of Mathematics Education Journal, 32.

Appelbaum, P. (2009). Taking action: Mathematics curricular organization for effective teaching and learning. For the Learning of Mathematics, 29(2), 39-44.

Barbosa, J. C. (2007). Teacher-student interactions in mathematical modelling. In C. Haines, P. Galbraith, W. Blum, \& S. Khan (Eds.), Mathematical modelling: Education, engineering and economics (ICTMA 12) (pp. 232-240). Woodhead. https://doi.org/ 10.1533/9780857099419.5.232

Barwell, R. (2013). The mathematical formatting of climate change: Critical mathematics education and post-normal science. Research in Mathematics Education, 15(1), 1-16. https://doi.org/10.108o/14794802.2012.756633

Barwell, R. (2018). Some thoughts on a mathematics education for environmental sustainability. In P. Ernest (Ed.), The philosophy of mathematics education today (pp. 145-16o). Springer. https://doi.org/10.10o7/978-3-319-7776o-3_9

Coles, A., Barwell, R., Cotton, T., Winter, J., \& Brown, L. (2013). Teaching secondary mathematics as if the planet matters. Routledge. https://doi.org/10.4324/9780203357286

English, L. D., \& Gainsburg, J. (2015). Problem solving in a 21st-century mathematics curriculum. In L. D. English \& D. Kirshner (Eds.), Handbook of international research in mathematics education (3rd ed., pp. 313-335). Routledge. https://doi.org/ 10.4324/9780203448946-21

English, L. D., \& Watson, J. (2018). Modelling with authentic data in sixth grade. ZDM Mathematics Education, 50(1-2), 103-115. https://doi.org/10.1007/s11858-017-0896-y 
Funtowicz, S. O., \& Ravetz, J. R. (1993). Science for the post-normal age. Futures, 25(7), 739-755. https://doi.org/10.1016/oo16-3287(93)90022-L

Hauge, K. H. (2016a). Usikkerhet i temperaturprognoser [Uncertainty in temperature prognoses]. In T. E. Rangnes \& H. Alrø (Eds.), Matematikklcering for framtida - Festskrift til Marit Johnsen-Høines (pp. 217-240). Caspar Forlag AS.

Hauge, K. H. (2016b). Matematikksamtaler om risiko [Mathematical conversations about risk]. In R. Herheim \& M. Johnsen-Høines (Eds.), Matematikksamtaler Undervisning og lcering - analytiske perspektiv (91-106). Caspar Forlag AS.

Hauge, K. H., \& Barwell, R. (2017). Post-normal science and mathematics education in uncertain times: Educating future citizens for extended peer communities. Futures, 91, 25-34. https://doi.org/10.1016/j.futures.2016.11.013

Hauge, K. H., Sørngård, M. A., Vethe, T. I., Bringeland, T. A., Hagen, A. A., \& Sumstad, M. S. (2015). Critical reflections on temperature change. In K. Krainer \& N. Vondrová (Eds.), Proceedings of the Ninth Conference of the European Society for Research in Mathematics Education (pp. 1577-1583). Charles University in Prague, Faculty of Education and ERME.

Intergovernmental Panel on Climate Change [IPCC]. (2018, October). Global warming of $1.5^{\circ} \mathrm{C}$. https://www.ipcc.ch/sr15/

Kaiser, G., \& Schwarz, B. (2010). Authentic modelling problems in mathematics education: Examples and experiences. Journal für Mathematik-Didaktik, 31(1), 51-76. https://doi.org/10.1007/s13138-010-0001-3

Pratt, D., Ainley, J., Kent, P., Levinson, R., Yogui, C., \& Kapadia, R. (2011). Role of context in risk-based reasoning. Mathematical Thinking and Learning, 13(4), 322-345. https://doi.org/10.108o/10986065.2011.608346

Skovsmose, O. (1994). Towards a critical mathematics education. Educational Studies in Mathematics, 27(1), 35-57. https://doi.org/10.1007/bfo1284527

Skovsmose, O. (2011). An invitation to critical mathematics education. Sense. https://doi.org/10.1007/978-94-6o91-442-3 